\title{
ЭВОЛЮЦИОННОЕ РАЗВИТИЕ И СТРУКТУРНОЕ РАЗНООБРАЗИЕ ПРИРОДНЫХ АНТИМИКРОБНЫХ ПЕПТИДОВ, ПЕПТИДОМИМЕТИКОВ И КАТИОННЫХ АМФИФИЛОВ НА ОСНОВЕ АМИНОКИСЛОТ
}

\author{
С. М. Филатова*, М.К. Гусева, Т. Г. Бодрова, Д. В. Паршина, У.А. Буданова, Ю. Л. Себякин \\ СВЕТЛАНА МИХАЙЛОВНА ФИЛАТОВА - магистр кафедры ХТБАСМиОХ им. Н.А. Преображенского РТУ \\ МИРЭА. Область научных интересов: синтез и свойства антимикробных пептидомиметиков. \\ E-mail: c221@yandex.ru.
}

МАРИЯ КОНСТАНТИНОВНА ГУСЕВА - магистр кафедры ХТБАСМиОХ им. Н.А. Преображенского РТУ МИРЭА. Область научных интересов: региоселективный синтез производных диэтилентриамина.

ТАТЬЯНА ГЕННАДЬЕВНА БОДРОВА - магистр кафедры ХТБАСМиОХ им. Н.А. Преображенского РТУ МИРЭА. Область научных интересов: химия биологически активных соединений, производные триптамина.

ДАРЬЯ ВАСИЛЬЕВНА ПАРШИНА - магистр кафедры ХТБАСМиОХ им. Н.А. Преображенского РТУ МИРЭА. Область научных интересов: биоорганическая химия.

УЛЬЯНА АЛЕКСАНДРОВНА БУДАНОВА - к.х.н., ассистент кафедры ХТБАСМиОХ им. Н.А. Преображенского РТУ МИРЭА. Область научных интересов: трансфекиия, модифицированные катионные липосомы, гибридные керасомы.

ЮРИЙ ЛЬВОВИЧ СЕБЯКИН - д. х. н., профессор кафедры ХТБАСМиОХ им. Н.А. Преображенского РТУ МИРЭА. Область научных интересов: химия биоконъюгатов, антимикробные пептиды, доставка лекарственных и генетических средств.

119571, Москва, Проспект Вернадского, д. 86, Институт тонких химических технологий им. М.В. Ломоносова, РТУ МИРЭА. E-mail: mirea@mirea.ru.

В обзорной статье прослежсиваются основные тенденции синтетического подхода к решению вопроса преодоления резистентности патогенных штаммов бактерий. Приведены основные стратегии поиска перспективных агентов, начиная с природных антимикробных пептидов или пептидов «защиты человека», с последующим эволючионным переходом к синтетическим пептидомиметикам макромолекулярного или олигомерного типов, а также подхода, основанного на мембранно-активных низкомолекулярных катионных амфифилах. Показано структурное многообразие пептидомиметиков с высокой бактерицидной активностью, обладающих повыщенной устойчивостью к действию протеолитических ферментов по сравнению с природными пептидами. Большое внимание уделено различным алифатическим и ароматическим катионным амфифилам на основе аминокислот. Отмечены потенциальные возможности этого класса соединений в качестве антимикробных агентов. Амфифильная структура синтезированных соединений позволяет им избирательно воздействовать на бактериальные мембраны и не приводит к запуску у бактерий прочесса развития резистентности.

Ключевые слова: резистентность, АМП, пептидомиметики, катионные амфифилы, антибактериальная активность, минимальная ингибирующая концентрация. 


\title{
EVOLUTIONARY DEVELOPMENT AND STRUCTURAL DIVERSITY OF NATURAL ANTIMICROBIAL PEPTIDES, PEPTIDOMETIC AND CATIONIC AMPHIPHILES BASED ON AMINO ACIDS
}

\author{
S. M. Filatova*, M. K. Guseva, T. G. Bodrova, D. V. Parshina, U.A. Budanova, Yu. L. Sebyakin \\ 78, Vernadsky Avenue, Moscow, 119454. MIREA - Russian Technology University (Lomonosov Institute of Fine \\ Chemical Technology).E-mail: c-221@yandex.ru.
}

\begin{abstract}
The review article traces the main tendencies of the synthetic approach to solving the problem of overcoming the resistance of pathogenic bacterial strains. The main strategies for searching for promising agents are presented, starting with natural antimicrobial peptides or peptides of "human defense", followed by an evolutionary transition to synthetic peptidomimetics of macromolecular or oligomeric types, as well as an approach based on membrane-active low molecular weight cationic amphiphiles. The structural diversity of peptidomimetics with high bactericidal activity and increased resistance to the action of proteolytic enzymes in comparison with natural peptides has been shown. Much attention is paid to various aliphatic and aromatic cationic amphiphiles based on amino acids. Potential capabilities of this class of compounds as antimicrobial agents were noted. The amphiphilic structure of the synthesized compounds allows them to selectively affect bacterial membranes and does not trigger the development of resistance in bacteria.
\end{abstract}

Keywords: resistance, AMP, peptidomimetics, cationic amphiphiles, antibacterial activity, minimum inhibitory concentration.

\section{Введение}

Устойчивость к антибиотикам в последние годы резко возросла и возникновение форм патогенных микроорганизмов с множественной лекарственной резистентностью становится серьёзной проблемой здравоохранения. Новые антибиотики разрабатываются относительно редко, но предлагается несколько вариантов решения проблемы резистентности, в частности, использование разработок в области биотехнологии, генной инженерии и синтетической химии. Особый интерес представляют природные и синтетические антимикробные пептиды (АМП). Способность АМП убивать или ингибировать рост бактерий привлекла внимание многих исследовательских групп по всему миру для изучения механизма их антимикробного действия. Считается, что положительный заряд и амфифильная структура позволяют им взаимодействовать с отрицательно заряженными компонентами и гидрофобными цепями жирных кислот в мембранах микроорганизмов-мишеней, что приводит к дестабилизации и, по-видимому, лизису клеток.

Однако АМП пока не получили широкого применения на практике. Это связано, прежде всего, с токсичностью и нестабильностью in vivo, потенциальной иммуногенностью и рядом других причин, среди которых дороговизна и сложность получения в промышленности. Данные недостатки послужили стимулом к разработке синтетических стратегий получения антимикробных пептидомиметиков (АМПм), которые имитируют физические свойства прототипов, но при этом сохраняют или даже повышают их антибактериальную активность. Поиск наиболее эффективных потенциальных антимикробных агентов путем модификации структуры катионных амфифилов и обнаружение закономерностей структура-активность является актуальной задачей современной науки.

\section{Антимикробные пептиды эндогенного происхождения}

С каждым годом пополняется список устойчивых к действию антибиотиков «приоритетных патогенов», вызывающих смертельно опасные инфекции. Этот список, названный «ESKAPE», опубликован Всемирной организацией здравоохранения (ВО3) и в отчете за 2017 год в него входило 12 видов бактерий $[1,2]$. Особую опасность представляют грамотрицательные бактерии, устойчивые 
к действию сразу нескольких антибиотиков, так как они способны формировать новые способы противодействия существующим лекарственным средствам, а также передавать их на генетическом уровне другим бактериям (рис. 1) [1, 2].

В 2019 году Центры по контролю и профилактике заболеваний США сообщили об особой опасности уже 18 видов микроорганизмов [3]. Их количество постоянно растёт, проблема набирает масштаб, что затрудняет лечение внутрибольничных и коллективных инфекций во всем мире $[4,5]$.

Список ВОЗ призван стать ориентиром и стимулом для научных исследований [2].

Особый интерес представляют природные и синтетические антимикробные пептиды (АМП), так как они являются потенциальными агентами для борьбы с микроорганизмами, обладающими множественной лекарственной устойчивостью [8].

АМП эндогенного происхождения являются важнейшей частью врожденного иммунитета, существуют в большинстве живых организмов и участвуют в иммунной защите от патогенов $[9,10]$. Они отличаются высокой эффективностью бактерицидного действия [10], а также обладают противовирусными, противогрибковыми, противоопухолевыми и антиоксидантными свойствами [11]. Выясняются механизмы, способствующие более эффективной реализации производных эндогенных пептидов в качестве терапевтических агентов $[12,13]$.

Таблица 1

Примеры АМП на III стадии клинических испытаний для внутривенного введения [13]

\begin{tabular}{cll}
\hline № & \multicolumn{1}{c}{ АМП } & Показания к применению \\
\hline 1 & Neuprex (rBPI21) & Детская менингококкемия \\
2 & POL7080 & P. aeruginosa, K. pпечтопia \\
3 & p2TA (AB103) & Некрозы мягких тканей \\
4 & Iseganan (IB-367) & Пневмония \\
\hline
\end{tabular}

Большинство АМП - это катионные при физиологических значения $\mathrm{pH}$ олиго- или полипептиды длиной от 12 до 50 аминокислотных остатков, из которых не менее 50 \% являются гидрофобными. Для них характерно высокое содержание полярных (Lys, Arg, His) и неполярных гидрофобных аминокислотных остатков (чаще всего Ala, Ile, Leu, Val) [14].

Все АМП, вне зависимости от их биологического происхождения, имеют относительно небольшой размер, линейную или циклическую структу-

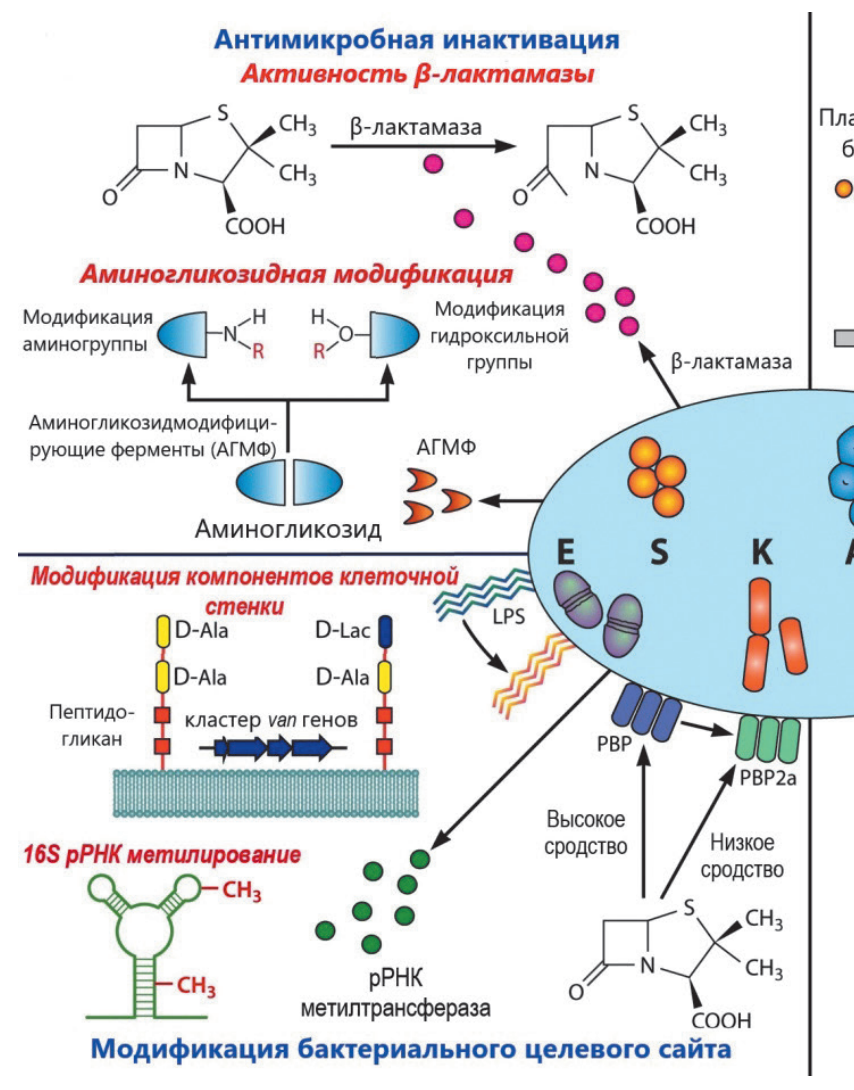

Рис. 1. Основные молекулярно-генетические механизмы устойчивости бактерий к противомикробным препаратам $[6,7]$ 

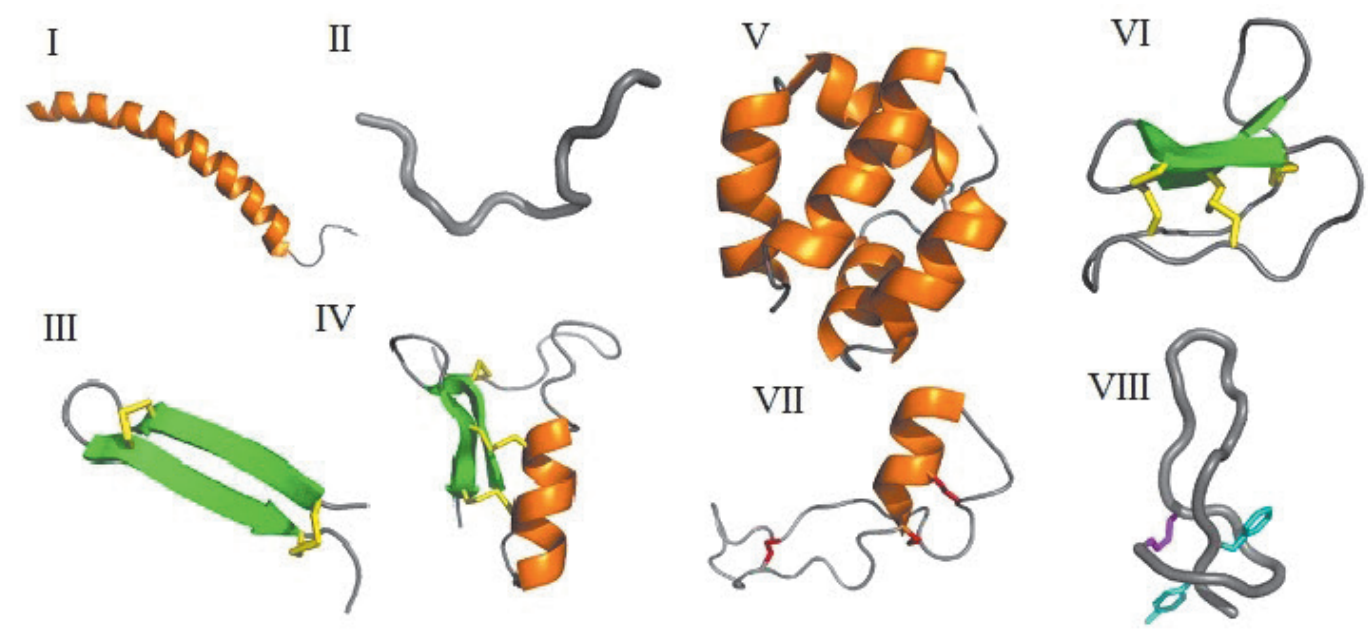

Рис. 2. Структурное разнообразие линейных (I-IV) и циклических (V-VIII) природных АMП [16]

ру и объединяются в четыре больших семейства. Линейная структура реализуется посредством амфипатических $\alpha$-спиралей, в то время как циклическая структура характеризуется наличием одного или нескольких дисульфидных мостиков, образующих $\beta$-складчатые листы (рис. 2) $[15,16]$.

Структура, соотношение и распределение заряженных, нейтральных, гидрофобных и гидрофильных аминокислотных остатков в молекуле АМП определяют суммарный положительный заряд, который, находясь в пределах от +2 до +9 , обеспечивает взаимодействие пептида с поверхностью микробной клетки, и амфифильность с пространственным разделением гидрофильного и гидрофобного блоков соединений, за счет чего они приобретают способность внедряться в клеточную стенку бактерий посредством взаимодействия с ее компонентами $[17,18]$. При этом, конкретный аминокислотный состав и последовательность аминокислот определяют пространственную структуру пептидов и разнообразие механизмов, лежащих в основе их антимикробных эффектов (рис. 3) [19].

Структурные особенности любой биомолекулы играют важнейшую роль в интерпретации степени ее биологической активности. Большое число проведенных за несколько десятилетий исследований зависимости «структура - активность» в ряду разнообразных антимикробных пептидов показывает, что уровень проявляемой антибактериальной активности является результатом единства действия множества факторов, среди которых следует отметить вторичную структуру, амфифильность, объем положительного заряда и величину гидрофобного фрагмента $[10,19,20]$.

Среди широкого разнообразия эндогенных антимикробных пептидных последовательностей су- ществуют эволюционно сохраненные признаки, обеспечивающие их активность на различных типах бактерий с различным составом клеточных стенок и, вероятно, несколькими вариантами механизма действия.

Состав аминокислотной последовательности в совокупности со специфической структурой боковых цепей определяют оптимальные терапевтические профили АМП и являются основой для разработки новых образцов для борьбы с инфекционными заболеваниями и их ликвидацией в будущем.

Наличие $\alpha$-спиральных структур в антимикробных пептидах, как правило, считается фактором, способствующим облегченному взаимодействию с бактериальными мембранами с последующим их лизисом. Соответственно, в процессе разработки разнообразных синтетических АМП с потенциальной антимикробной активностью в схему активно включают такие специфические аминокислоты как L-аланин, L-лейцин, L-аргинин, $\mathrm{L}$-лизин, которые проявляют высокую склонность к формированию $\alpha$-спиралей в составе аминокислотной последовательности [21].

Отличительной особенностью большинства антимикробных пептидов является их катионная природа, определяемая числом положительно заряженных остатков аминокислот. Положительному заряду отводится главная роль при взаимодействии между пептидами и отрицательно заряженными поверхностями бактериальных мембран через электростатические взаимодействия. Например, замена нескольких остатков L-аргинина в определенных позициях исследуемых образцов на остатки L-аланина или даже L-лизина снижала их антимикробную активность. Более того, на примере человеческих $\alpha$ - и $\beta$-дефенсинов было показано, 


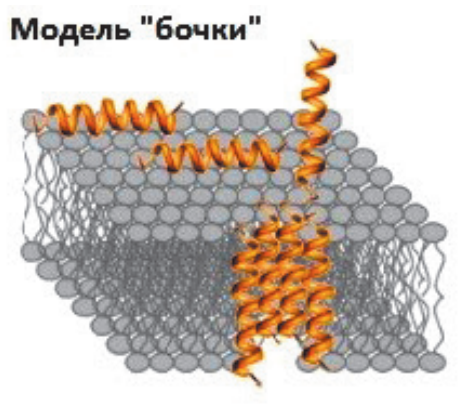

Модель "ковра"

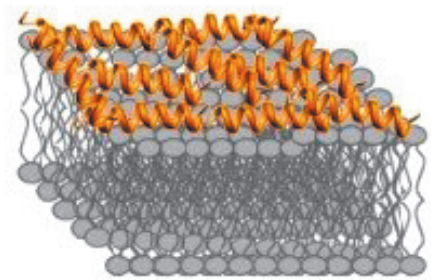

Модель тороидальной поры
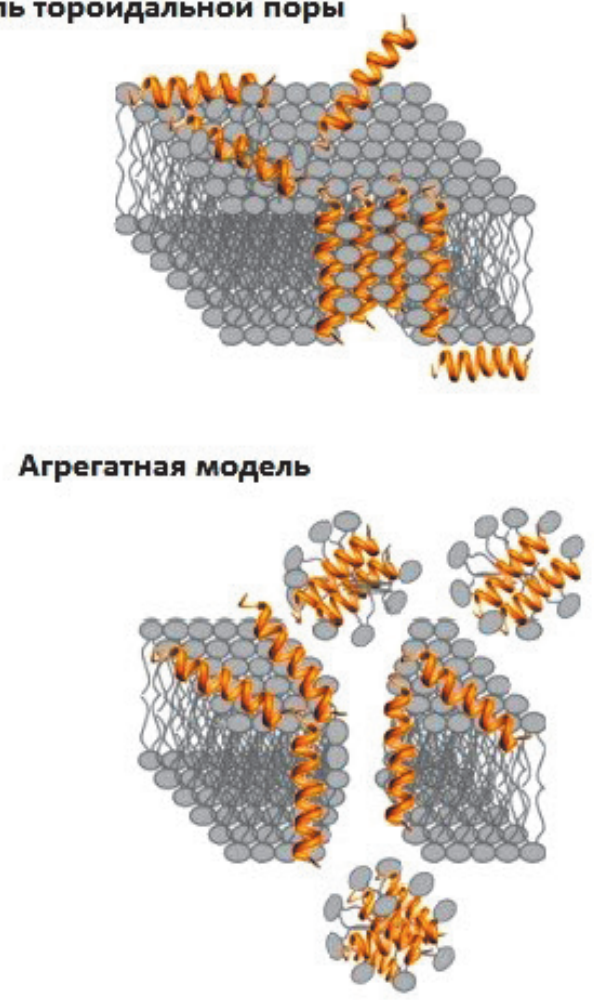

Рис. 3. Графическое изображение основных механизмов действия АМП

что общий положительный заряд не является основной детерминантой наблюдаемой эффективности, и при изменении заряда с +3 на +5 в структуре аналогов магайнина-2 наблюдали рост антибактериальной активности пептидов в отношении как грамположительных, так и грамотрицательных бактерий, а дальнейшее повышение заряда до +7 приводило к потере антибактериальной активности и увеличению гемолитической активности [21].

Гидрофобность, безусловно, является важнейшей функциональной особенностью рассматриваемого класса биологически активных соединений, т.к. она определяет потенциал и характер взаимодействия АМП с различными мембранными композициями бактерий, а также степень включения в липидный бислой. Незначительные изменения гидрофобности могут резко влиять на эффективность взаимодействия с мембраной и проникающую способность контрольных образцов. В частности, повышенная гидрофобность хорошо коррелирует с потерей антибактериальной специфичности, что приводит к высокой токсичности по отношению к клеткам млекопитающих [5, 21].

Амфифильность антимикробных пептидов, существующих в конформациях $\beta$-складчатого листа, достигается определенным соотношением между двумя различными полярными и непо- лярными доменами. Стабилизация $\beta$-складчатого слоя в антимикробных пептидах обеспечивает высокую конформационную жесткость в водном растворе. Такая конструкция позволяет аналогам АМП успешно взаимодействовать с клетками-мишенями и разрушать мембраны путем образования трансмембранных каналов [20, 21].

Несмотря на множество очевидных достоинств, АМП пока не получили широкого применения на практике. Это связано, прежде всего, с токсичностью и неоднозначной активностью in vivo, потенциальной иммуногенностью и рядом других причин, среди которых дороговизна и сложность крупномасштабного способа получения в промышленности.

\section{Синтетические пептидомиметики}

Данные недостатки послужили стимулом к разработке синтетических стратегий получения антимикробных пептидомиметиков (АМПм) [22, 23], которые имитируют физические свойства прототипов.

Разработаны такие структуры как $\alpha$-пептиды, $\beta^{3}$-пептиды, $\alpha$-пептоиды, $\beta$-пептоиды, $\alpha / \beta$-пептиды, $\alpha$-пептидные $/ \beta$-пептоидные гибриды, $\alpha$-АА пептиды, $\gamma$-АА пептиды, $\alpha / \beta$-олигоациллизины и другие [13]. 
Различные стратегии поиска перспективных агентов, применяемые исследовательскими группами, могут быть разделены на несколько категорий. Это макромолекулярный и олигомерный подходы, а также направление, основанное на низкомолекулярных структурах пептидомиметиков.

Макромолекулярный или полимерный подход для получения активных антимикробных средств на основе синтетических образцов получил достаточно широкое распространение. Необходимой основой для конструирования целевых соединений послужили два параметра АМП - катионная природа биополимера и амфифильность. В результате, в дизайне большинства разработок заложены следующие закономерности: хаотичное распределение гидрофильного и гидрофобного блоков по длине биополимера [24], объединение липофильных и полярных фрагментов в одном сегменте повторяющегося звена - структура с одним центром [25] или присутствие разделенных липофильных и полярных фрагментов одновременно в одном и том же повторяющемся звене - амфифильный метод [26].

Некоторые макромолекулярные АМПм в сочетании с другими лекарственными средствами обладают противогрибковой и антибиопленочной активностью, а также способны обеспечить эффективную доставку в клетки ми-РНК $[27,28]$.

В основе олигомерного метода получения новых пептидомиметиков сосредоточены разнообразные модификации структуры пептида, либо путем удлинения $\alpha$-пептидов [29] до $\beta$-пептидов, либо путем замены амидных связей производными мочевины [30], или пептоидной связью, либо замещением другими фрагментами молекул $[31,32]$.

Важный вклад в это направление внесли олигоациллизины [33] и $\alpha$-АА пептиды [34]. Модификацию пептидных связей в структуре пептидомиметиков проводят при сохранении достаточной амфифильности и суммарного положительного заряда целевых соединений. Это обеспечивает олигомерным продуктам способность образовывать вторичные структуры, необходимые для потенциального проявления антимикробной активности. От- сутствие лабильных первичных амидных связей делает эти пептиды устойчивыми к ферментативному разложению $[9,35,36]$.

Предложена серия $\alpha /$ сульфоно- $\alpha$-АА-пептидомиметиков с гидрофобными алифатическими фрагментами с МИК 1 мкг/мл в отношении MRSA. Используя флуоресцентную микроскопию с техникой деполяризации, авторы продемонстрировали способность синтезированных соединений разрушать клеточные стенки бактерий, оставаясь нетоксичными для человеческих эритроцитов [37].

\section{Мембрано-активные низкомолекулярные катионные амфифилы}

Перспективность макромолекулярного и олигомерного методов в разработке имитаторов антимикробных пептидов достаточно хорошо подтверждена результатами лабораторных исследований и обеспечила базу для разработок нового класса антимикробных препаратов с аналогичными функциями на основе синтетических мембранноактивных низкомолекулярных катионных амфифилов (sAMPm) [18, 38-43].

Ключевыми структурными особенностями малых катионных молекул является состав из 2-5 аминокислотных остатков, суммарный заряд +2 и обязательное наличие нескольких гидрофобных фрагментов. Катионные амфифилы имеют небольшие размеры и несложную химическую структуру. Они легко адсорбируются на границе раздела твердой и жидкой фаз и способны взаимодействовать с клеточными мембранами микроорганизмов. В данной связи, катионные амфифилы обладают большим терапевтическим потенциалом в качестве антимикробных и противогрибковых средств.

Необходимо отметить, что около $90 \%$ лекарств, используемых сегодня на рынке, представляет собой малые молекулы: они обладают большим диапазоном биологической активности, их относительно просто синтезировать и производить в промышленном масштабе. Из них легко формировать таблетки и капсулы, которые при растворении бес-

Таблица 2

Аминокислотная последовательность синтетических пептидов и значения МИК

\begin{tabular}{lccc}
\hline \multirow{2}{*}{ контроль } & Пептидомиметики & \multicolumn{2}{c}{ МИК $(\boldsymbol{\mu g} / \mathbf{m l})$} \\
\cline { 3 - 4 } & RWKLFKKIEKVGRNVRDGLIKAGPAIAVIGQAKSLGK & $\boldsymbol{K}$. pneumoniae & $\boldsymbol{P .}$ aeruginosa \\
\hline & RWKIFKKIEKMGRNIRDGIVKAGPAIEVLGSAKAIGK & 12,5 & 6,25 \\
\hline Ампициллин & & $>100$ & 6,25 \\
\hline
\end{tabular}


препятственно попадают в кровоток через стенку кишечника и быстро выводятся из организма [14].

Структура катионного амфифила представляет собой комбинацию из гидрофобного и гидрофильного блоков, которые соединены спейсерными группами посредством химической связи определенного типа (линкерами).

Поиск наиболее эффективных потенциальных антимикробных агентов проводится путем модификации структуры катионных амфифилов, которая включают изменение компоновки фрагментов, природы катионного или гидрофобного доменов и варьирование спейсерных и линкерных групп.

На этой основе создано широкое композиционное многообразие разработанных и исследованных вариантов SAMPm (рис. 4, 5).

Прежде всего, это классические молекулы по типу I, II - «голова-хвост» (рис. 4). В полярной части может присутствовать одна или несколько положительно заряженных группировок, которые часто представлены аминокислотными остатками.

Низкомолекулярные катионные липопептиды напоминают широко применяемые в санитарии антимикробные поверхностно-активные вещества (детергенты) с их неизбирательностью действия, однако, наличие L-аминокислот и возможность достаточно легкого и прогнозируемого варьирования структуры гидрофобного блока снижают большинство побочных эффектов.

Липоаминокислоты на основе длинноцепочечных алифатических производных L-аргинина проявляют активность против грамположительных и грамотрицательных бактерий [44]. При этом наблюдается более низкий уровень цитотоксичности и гемолитической активности, нежели у известных средств бензалкония хлорида и цетримида при сопоставимом уровне минимальной ингибирующей концентрации [45]. Дипептидомиметики [46] и липопептиды с остатками L-орнитина или L-аргинина, в количестве от 2 до 5, проявляют высокую антимикробную активность с МИК 1,5-4,5 мкг/мл и 1,566,25 мкг/мл, соответственно [47, 48].

Молекулы могут иметь симметрию, что позволяет создавать гемини-амфифилы (рис. 4, тип III) - соединения, в структуре которых два гидрофобных фрагмента связаны через спейсерный блок с гидрофильным доменом [14, 49]. Получаемые с помощью данной стратегии гемини-амфифилы могут содержать в качестве гидрофобного домена остаток холестерина или производного холевой кислоты [45].

Болаамфифилы - это конструкции, в которых две катионные группировки разделены длинным спейсерным остовом (рис. 4, тип IV). Они могут проявлять не только самостоятельную антибактериальную активность [50], но и формировать эффективные наноразмерные транспортные системы доставки антисмысловых олигонуклеотидов. Подобные «боласомы» - антибактериальные комплексы предложено использовать при лечении заболеваний, вызванных патогенными грамположительными спорообразующими анаэробными бактериями Clostridium difficile [51], и в других вариантах терапевтической биотехнологии $[52,53]$.

Описанные в литературе бис-катионные амфифилы с одним гидрофобным фрагментом различаются по природе полярного звена и длиной алифатической цепи (рис. 4, тип V) $[54,55]$. Кроме того,

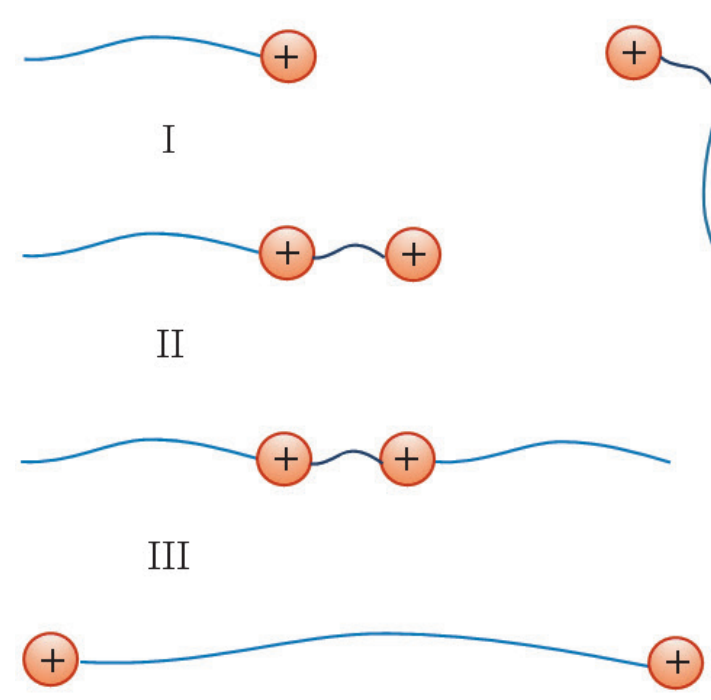

IV

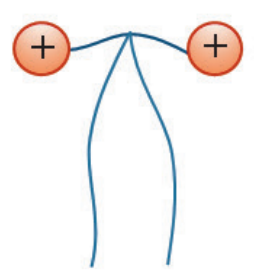

$\mathrm{VI}$

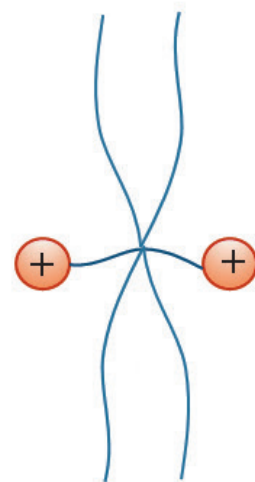

VIII

Рис. 4. Схематичное изображение структур алифатических катионных амфифилов 


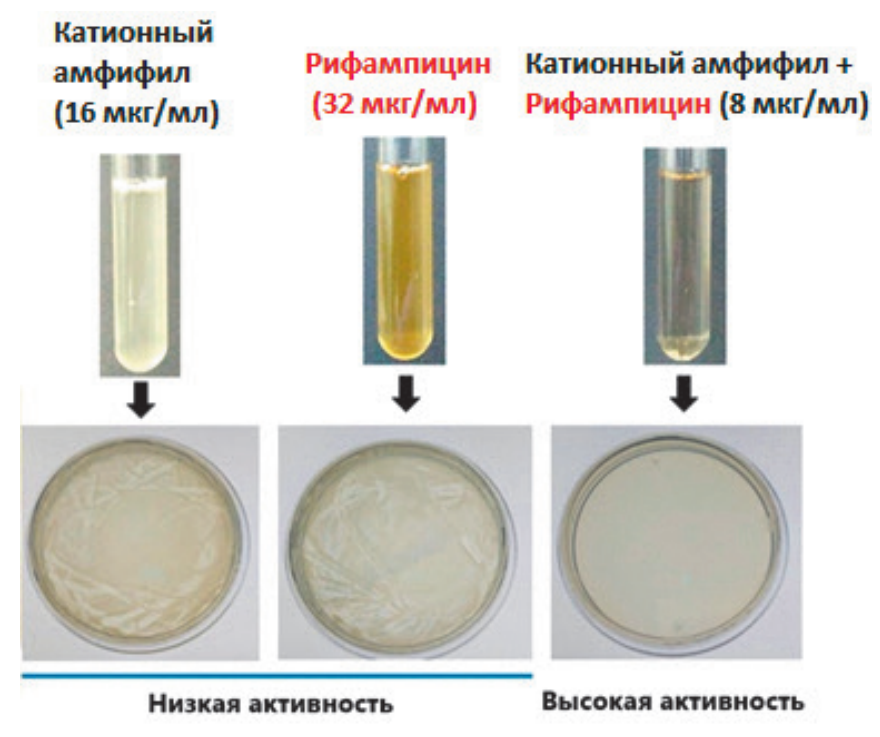

Рис. 5. Сравнительный анализ биологической активности (МИК) при индивидуальном

и совместном использовании катионного амфифила и рифампицина [56]

отмечается синергизм при использовании амфифилов этого типа совместно с традиционными антибиотиками, значительно усиливающий активность каждого индивидуального компонента (рис. 5) [56].

Трикатионные производные $\beta$-аминокислот с остатками L-орнитина/L-аргинина в полярной части активны против грамположительных и грамотрицательных бактерий, стабильны в плазме человека, обладают селективностью против прокариотов и позволяют контролировать инфекцию, увеличивая выживаемость мышей с модельным сепсисом [57].

Проведено системное изучение «структура-активность» серии из диалкил-катионных амфифилов (21 объект), синтезированных по реакции производных вторичных аминов с попарно одинаковыми алифатическими радикалами длиной $\mathrm{C}_{6}-\mathrm{C}_{14}$ и с девятью разными L- или $\mathrm{D}$-аминокислотами для формирования полярного блока (рис. 4, тип VI) [58].

Семнадцать соединений из этой серии проявили высокую антибактериальную активность широкого спектра действия, в том числе, по отношению к резистентным штаммам бактерий. Ряд образцов имел уровень активности, сопоставимый с контрольным ванкомицином. Исследования подтвердили, что амфифильность является ключевым параметром для проявления активности, особенно против грамотрицательных бактерий. Образцы с длиной углеводородных радикалов $\mathrm{C}_{7}-\mathrm{C}_{9}$ оказались практически нетоксичными в отношении эритроцитов.
Подобные структуры с L-аргинином в полярном блоке и сложноэфирной связью в качестве линкера также продемонстрировали отсутствие значимых побочных эффектов [45] и синергизм антимикробной активности в экспериментах in vitro и in vivo [59].

На примере бис-катионных соединений [60, 61], относящихся по структуре к гемини-подобным амфифилам (рис. 4, тип VII, VIII) прослеживается роль типа линкерной связи (простая или сложноэфирная связь) при одних и тех же двух заряженных доменах, что в конечном итоге определяет гидрофильно-липофильный баланс молекулы [62].

Введение в структуру амфифилов ароматических аминокислот значительно влияет на проявление антимикробной активности. Арильные фрагменты в определенных доменах катионных молекул являются общей чертой многочисленных исследований по поиску оптимальной структуры низкомолекулярных пептидомиметиков. Ароматические группировки используется для варьирования объема гидрофобного блока и баланса «гибкость-жесткость» соответствующих фрагментов. При этом возможно частичное или полное замещение алифатических цепей в гидрофобном блоке, а также формирование совмещенных гибридных конструкций (рис. 6, тип IX-XVII) [63-75].

Предложены липофильные фенилаланин-норспермидиновые конъюгаты (рис. 6, тип IX). Синтезированные соединения, содержащие алифатические фрагменты разной длины и L/D-аминокислоты в полярном домене, показывали более широкий спектр антимикробной активности по сравнению с липопептидным антибиотиком колистином [65].

При изучении антимикробной активности пептидомиметиков типа XI (рис. 6) было обнаружено, что ряд соединений обладает противоопухолевой активностью, уровень которой также определялся гидрофобностью амфифилов.

Сформирована «библиотека» катионных амфифилов, содержащих разнообразные алифатические фрагменты и ароматические радикалы. На широкой панели мультирезистентных грамположительных и грамотрицательных бактериальных штаммов для синтезированных образцов продемонстрирован хороший потенциал. Отмечается предотвращение воспаления у крыс, вызванное MRSA-индуцированной пневмонией (МИК не ниже 6,25 мкг/мл на всех штаммах, а для MRSA - 1,56 мкг/мл). Соединения также способны подавлять образование и развитие биопленки, вызванное бактериями E. coli, даже в концентрации 0,6 мкг/мл и A. baumannii-2 мкг/мл [66].

Изучение зависимости «структура - активность» на серии объектов тип XV (рис. 6) показало, 


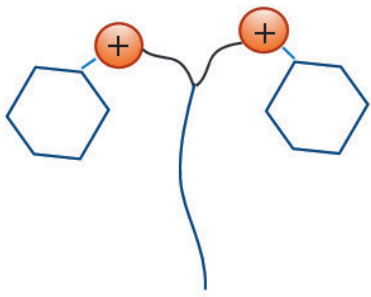

IX

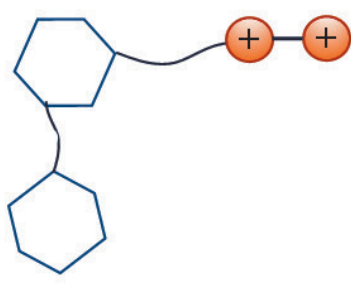

X

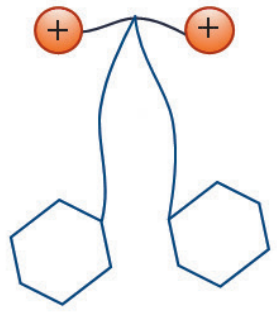

XI

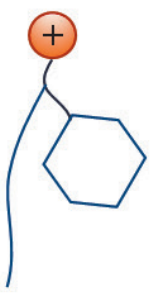

XII
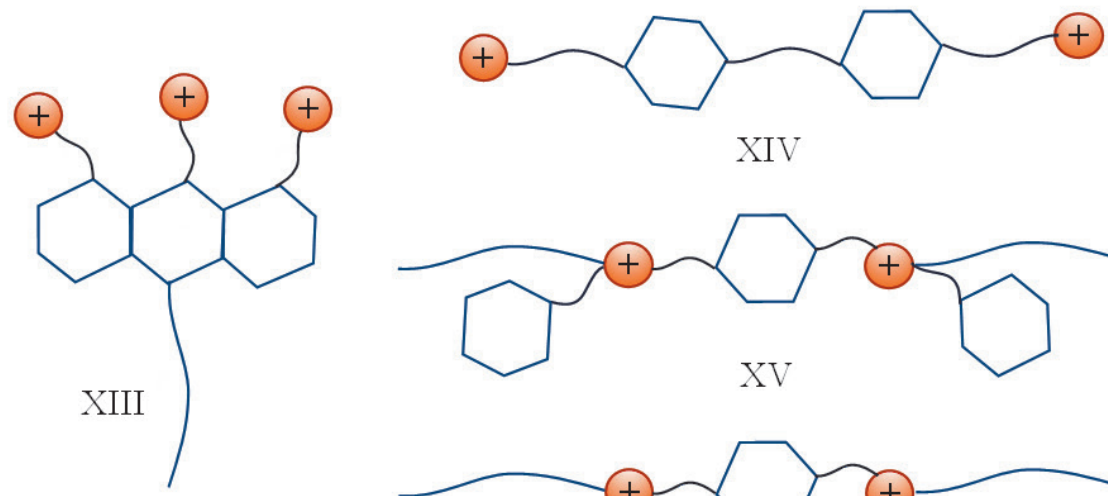

XIV

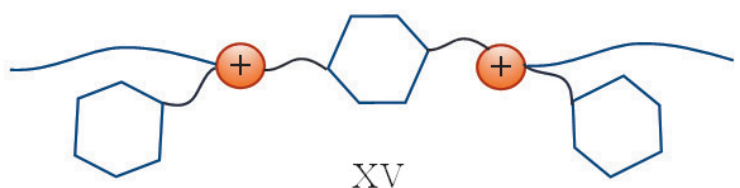

XV
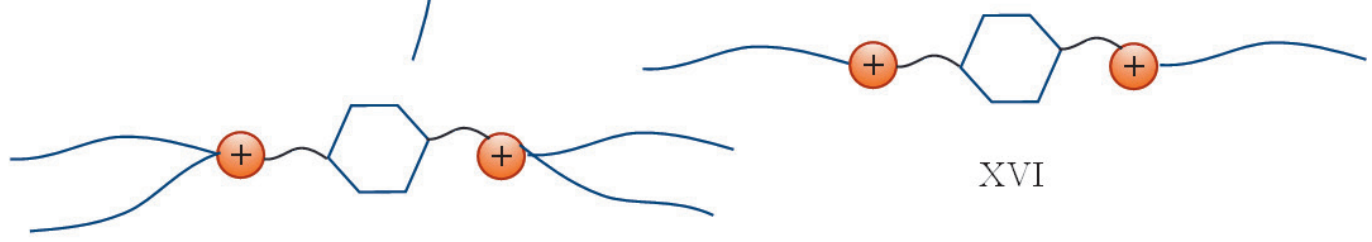

XVI

XVII

Рис. 6. Схематичное изображение структур ароматических катионных амфифилов

что повышение суммарного заряда путем добавления остатка L-лизина не всегда приводит к увеличению активности, а замена L-лизина на L-орнитин понижает эффективность процесса. Авторы предполагают, что механизм действия аналогичен защите природных АМП, для соединений-лидеров резистентность у бактерий MRSA не возникает даже после 14 пассажей [66].

Разработана серия производных $\boldsymbol{M}$ - и $n$-фенилендиаминов и терефталевой кислоты в качестве спейсера и остатками L-лизина в полярных доменах. После оптимизации длины углеводородных радикалов соединения-лидеры продемонстрировали практически идентичную активность против всех протестированных штаммов грамположительных бактерий по сравнению с даптомицином, который является антибиотиком последней инстанции, и активность в отношении штаммов грамотрицательных бактерий аналогичную колистину. Данные флуоресцентной микроскопии подтвердили способность этих соединений разрушать мембраны как грамположительных, так и грамотрицательных бактерий. При этом, режим разрушения микроорганизмов был аналогичен действию природных АМП [69].
Авторы отмечают, что амфифильная структура синтезированных соединений позволяет им избирательно воздействовать на бактериальные мембраны и не приводит к запуску у бактерий процесса развития резистентности. Димеризация структуры синтезированных соединений обоснована простотой химического синтеза. Данная стратегия представляется многообещающей и, как ожидается, может привести к созданию нового поколения антибиотиков мембранно-активного действия для борьбы с возникающей устойчивостью к традиционным антибиотикам.

\section{Заключение}

За последнее десятилетие достигнут значительный прогресс в разработке антимикробных пептидомиметиков, имитирующих бактерицидное действие с повышенной ферментативной устойчивостью по сравнению с АМП.

Пептидомиметики представляют собой перспективный класс соединений, обладающих значительной антибактериальной активностью, в том числе против ESKAPE-патогенов, которая обусловливает их включение в новое поколение антими- 
кробных агентов после АМП. Основной задачей при проведении исследований in vivo является снижение гемолитической активности и цитотоксичности анализируемых образцов. Важнейшими факторами, которые определяют эффективность их антимикробного действия, являются выбор структурных компонентов, расчет расстояния между положительными зарядами и объем гидрофобного блока. Дальнейшее развитие получают молекулярный дизайн пептидомиметиков и изучение возможностей их прямого медицинского применения.

Большое внимание привлекают синтетические мембранно-активные низкомолекулярные катионные амфифилы. Рядом экспериментов продемонстрированы потенциальные возможности этого класса соединений в качестве антимикробных агентов. Несложная химическая структура SAMPm представляет собой комбинацию из гидрофобного и гидрофильного блоков, которые соединены спейсерными группами посредством химической связи определенного типа. Оптимальная антимикробная активность образцов достигается «тонкой настройкой» длины гидрофобных цепей амфифила, наличием ароматического фрагмента и величиной положительного заряда.

Структурное многообразие и полученные результаты по уровню эффективности соединенийлидеров позволяют надеяться в ближайшем будущем на конструирование перспективных агентов с высоким уровнем биологической активности для нужд медицины.

\section{Лuтература}

1. Tacconelli E., Magrini N., Kahlmeter G., and Singh N. Global priority list of antibiotic-resistant bacteria to guide research, discovery, and development of new antibiotics // World Health Organization. 2017. V. 27. P. 318-327.

2. Tacconelli E., Carrara E., Savoldi A., Harbarth S., Mendelson M., Monnet D.L., Carmeli, Y. Discovery, research, and development of new antibiotics: the WHO priority list of antibiotic-resistant bacteria and tuberculosis. Lancet Infect. Dis. 2018. V. 18. P. 318-327. doi: 10.1016/s1473-3099(17)30753-3.

3. Centers for Disease Control and Prevention. Antibiotic Resistance Threats in the United States. Atlanta, GA: US Department of Health and Human Services, CDC. 2019. doi: 10.15620/cdc:82532.

4. Cerceo E., Deitelzweig S.B., Sherman B.M., Amin A.N. Multidrug-Resistant Gram-Negative Bacterial Infections in the Hospital Setting: Overview, Implications for Clinical Practice, and Emerging Treatment Options. Microb. Drug. Resist. 2016. V. 22. P. 412-431. doi: 10.1089/mdr.2015.0220.

5. Wang $G$. Database-guided discovery of potent peptides to combat HIV-1 or superbugs. Pharmaceuticals. 2013. V. 6. P. 728-758. doi: 10.3390/ph6060728.
6. De Oliveira D.M., Forde B.M., Kidd T.J., Harris P.N., Schembri M.A., Beatson S.A., Walker M.J. Antimicrobial Resistance in ESKAPE Pathogens. 2020. Clin. Microbiol. Rev. 2020. V. 33. P. 1-49. doi: 10.1128/ CMR.00181-19.

7. Santajit S., Indrawattana N. Mechanisms of Antimicrobial Resistance in ESKAPE Pathogens. BioMed Res. Int. 2016. V. 2016. P. 1-8. doi: 10.1155/2016/2475067.

8. Tincho M.B., Morris T., Meyer M., and Pretorius A. Antibacterial Activity of Rationally Designed Antimicrobial Peptides. Int. J. Microbiol. 2020. V. 2020. P. 1-9. doi: 10.1155/2020/2131535.

9. Giuliani A., Rinaldi A.C. Beyond natural antimicrobial peptides: multimeric peptides and other peptidomimetic approaches. Cell. Mol. Life Sci. 2011. V. 68. P. 22552266. doi: 10.1007/s00018-011-0717-3.

10. Amerikova M., Pencheva El-Tibi I., Maslarska V., Bozhanov S., Tachkov K. Antimicrobial activity, mechanism of action, and methods for stabilisation of defensins as new therapeutic agents. Biotechnol. Biotechnolog. Equip. 2019. V. 33. P. 671-682. doi: 10.1080/13102818.2019.1611385.

11. Seyfi R., Kahaki F.A., Ebrahimi T., Montazersaheb S., Eyvazi S., Babaeipour V., Tarhriz V. Antimicrobial Peptides (AMPs): Roles, Functions and Mechanism of Action. Int. J. Pept. Res. Ther. 2019. V. 26. P. 1451-1463. doi: 10.1007/s10989-019-09946-9.

12. Bechinger B., Gorr S.-U. Antimicrobial Peptides: Mechanisms of Action and Resistance. J. Dent. Res. 2016. V. 96. P. 254-260. doi: 10.1177/0022034516679973.

13. Molchanova N., Hansen P.R., Franzyk H. Advances in Development of Antimicrobial Peptidomimetics as Potential Drugs. Molecules. 2017. V. 22. P. 1430. doi: 10.3390/molecules22091430.

14. Ghosh C., Haldar J. Membrane-Active Small Molecules: Designs Inspired by Antimicrobial Peptides. ChemMedChem. .2015. V. 10. P. 1606-1624. doi: 10.1002/cmdc.201500299.

15. Musin Kh.G. Antimicrobial peptides - a potential replacement for traditional antibiotics. Russian Journal of Infection and Immunity = Infektsiya i immunitet. 2018. V. 8. P. 295-308. doi: 10.15789/2220-7619-2018-3-295-308.

16. Koehbach J. and Craik D.J. The Vast Structural Diversity of Antimicrobial Peptides. Trends Pharmacol. Sci. 2019. V. 40. P. 517-528. doi: 10.1016/j. tips.2019.04.012.

17. Singh P., Hockenberry A.J., Tiruvadi V.R., Meaney D.F. Computational investigation of the changing patterns of subtype specific NMDA receptor activation during physiological glutamatergic neurotransmission. PLoS Comput. Biol. 2011. V. 7. P. 1-17. doi: 10.1371/journal. pcbi.1002106.

18. Denieva Z.G., Romanova N.A., Bodrova T.G., Budanova U.A., Sebyakin Y.L. Synthesis of Amphiphilic Peptidomimetics Based on the Aliphatic Derivatives of Natural Amino Acids. Moscow Univ. Chem. Bull. V. 74. P. 300-305. doi: 10.3103/s0027131419060087.

19. Kumar P., Kizhakkedathu J.N., Straus S.K. Antimicrobial peptides: diversity, mechanism of action and strategies to improve the activity and biocompatibility 
in vivo. Biomolecules. 2018. V. 8. P. 1-24. doi: 10.3390/ biom8010004.

20. Raheem N., Straus S.K. Mechanisms of Action for Antimicrobial Peptides With Antibacterial and Antibiofilm Functions. Front. Microbio. 2019. V. 10. P. 1-14. doi: 10.3389/fmicb.2019.02866.

21. Mojsoska B., Jenssen H. Peptides and peptidomimetics for antimicrobial drug design. Pharmaceuticals. V. 8. P. 366-415. doi: 10.3390/ph8030366.

22. Qvit N., Rubin S.J.S., Urban T.J., Mochly-Rosen D., Gross E.R. Peptidomimetic therapeutics: scientific approaches and opportunities. Drug Discov. Today. 2017. V. 22. P. 454-462. doi: 10.1016/j.drudis.2016.11.003.

23. Dias C., Rauter A.P. Membrane-targeting antibiotics: recent developments outside the peptide space. Fut. Med. Chem. 2019. V. 11. P. 211-228. doi: 10.4155/fmc2018-0254.

24. Kuroda K., Caputo G.A. Antimicrobial polymers as synthetic mimics of host-defense peptides. Wiley Interdiscip. Rev.: Nanomed. Nanobiotechnol. 2013. V. 5. P. 49-66. doi: 10.1002/wnan.1199.

25. Uppu D. S., Akkapeddi P., Manjunath G. B., Yarlagadda V., Hoque J., Haldar J. Polymers with tunable sidechain amphiphilicity as non-hemolytic antibacterial agents. Chem. Commun. 2013. V. 49. P. 9389-9391. doi: 10.1039/C3CC43751E.

26. Engler A.C., Wiradharma N., Ong Z.Y., Coady D.J., Hedrick J.L., Yang Y.Y. Emerging trends in macromolecular antimicrobials to fight multi-drug-resistant infections. Nano Today. 2012. V. 7. P. 201-222. doi: 10.1016/j.nantod.2012.04.003.

27. Nadithe V., Liu R., Killinger B.A., Movassaghian S., Kim N.H., Moszczynska A.B., and Merkel O.M. Screening nylon-3 polymers, a new class of cationic amphiphiles, for siRNA delivery. Mol. Pharm. 2015. V. 12. P. 362-374. doi: 10.1021/mp5004724.

28. Liu R., Chen X., Falk S.P., Mowery B.P., Karlsson A.J., Weisblum B., and Gellman S.H. Structure-activity relationships among antifungal nylon-3 polymers: identification of materials active against drug-resistant strains of Candida albicans. J. Am. Chem. Soc. 2014. V. 136. P. 4333-4342. doi: 10.1021/ja500036r.

29. Chen Y., Mant C. T., Farmer S.W., Hancock R.E., Vasil M.L., and Hodges R.S. Rational design of $\alpha$-helical antimicrobial peptides with enhanced activities and specificity/therapeutic index. J. Boil. Chem. 2005. P. 280. P. 12316-12329. doi: 10.1074/jbc.M413406200.

30. Violette A., Averlant-Petit M.C., Semetey V., Hemmerlin C., Casimir R., Graff R., Guichard G. N, N'-Linked Oligoureas as Foldamers: Chain Length Requirements for Helix Formation in Protic Solvent Investigated by Circular Dichroism, NMR Spectroscopy, and Molecular Dynamics. J. Am. Chem. Soc. 2005. V. 127. P. 2156-2164. doi: 10.1021/ja044392b.

31. Chongsiriwatana N.P., Patch J.A., Czyzewski A.M., Dohm M.T., Ivankin A., Gidalevitz D., and Barron A.E. Peptoids that mimic the structure, function, and mechanism of helical antimicrobial peptides. Proc. Natl. Acad. Sci. 2008. V. 105. P. 2794-2799. doi: 10.1073/ pnas. 0708254105 .
32. Sebyakin Yu. L., Loseva A.A., Budanova U.A., Lubeshkin $A . V$. Synthesis of dipeptide and carbohydrate ivermectin b1 derivatives. Macroheterocycles. 2016. V. 9. P. 314-319. doi: 10.6060/mhc160644s.

33. Radzishevsky I. S., Rotem S., Bourdetsky D., NavonVenezia S., Carmeli Y., and Mor A. Improved antimicrobial peptides based on acyl-lysine oligomers. Nat. Biotechnol. 2007. V. 25. 657-659. doi: 10.1038/ nbt1309.

34. Padhee S., Hu Y., Niu Y., Bai G., Wu H., Costanza F., and Cai J. Non-hemolytic $\alpha$-AApeptides as antimicrobial peptidomimetics. Chem. Commun. 2011. V. 47. P. 9729-9731. doi: 10.1039/C1CC13684D.

35. Lienkamp K., Madkour A. E., and Tew G. N. Antibacterial peptidomimetics: polymeric synthetic mimics of antimicrobial peptides. Polymer composites-polyolefin fractionation-polymeric peptidomimetics-collagens. 2010. V. 251. P. 141-172. doi: 10.1007/12_2010_85.

36. Meir O., Zaknoon F., Cogan U., and Mor A. A broadspectrum bactericidal lipopeptide with anti-biofilm properties. Sci. Rep. 2017. V. 7. P. 1-11. doi: 10.1038/ s41598-017-02373-0.

37. Singh S., Wang M., Gao R., Teng P., Odom T., Zhang $E$., and Cai $J$. Lipidated $\alpha /$ Sulfono- $\alpha$-AA heterogeneous peptides as antimicrobial agents for MRSA. Bioorg. Med. Chem. 2020. V. 28. P. 115241. doi: 10.1016/j. bmc.2019.115241.

38. Mahlapuu M., Björn C., and Ekblom J. Antimicrobial peptides as therapeutic agents: opportunities and challenges. Crit. Rev. Biotechnol. 2020. V. 40. P. 978-992. doi: 10.1080/07388551.2020.1796576.

39. Kundu $R$. Cationic amphiphilic peptide: A natureinspired synthetic antimicrobial peptide. ChemMedChem. 2020. V. 15. P. 1887-1896. doi: 10.1002/ cmdc. 202000301.

40. Wang M., Gao R., Sang P., Odom T., Zheng M., Shi Y., Cai J. Dimeric $\gamma$-AA peptides With Potent and Selective Antibacterial Activity. Front. Chem. 2020. V. 8. P. 1-11. doi: 10.3389/fchem.2020.00441.

41. Oliva R., Chino M., Pane K., Pistorio V., De Santis A., Pizzo E., Petraccone L. Exploring the role of unnatural amino acids in antimicrobial peptides. 2018. Sci. Rep. V. 8. P. 1-16. doi: 10.1038/s41598-018-27231-5.

42. Okorochenkov S.A., Zheltukhina G.A., Nebol'sin V.E. Antimicrobial peptides: mode of action and perspectives of practical application. Biomeditsinskaya Khimiya. 2012. V. 58. P. 131-143. doi: 10.18097/ pbmc20125802131.

43. Filatova S.M., Denieva Z.G., Budanova U.A., Sebyakin Y.L. Synthesis of low-molecular-weight antibacterial peptide mimetics based on dialkyl- and diacylamines. Moscow university chemistry bulletin. 2020. V. 75 (6). C. 320-327. doi: 10.3103/S0027131420060048.

44. Marusova (Soloveva) V.V., Zagitova R.I., Budanova U.A., Sebyakin Y.L. Multifunctional ipoamino acid derivatives with potential biological activity. Moscow Univ. Chem. Bull. 2018. V. 73. P. 74-79. doi: 10.3103/ S0027131418020098.

45. Shahzadi I., Jalil A., Asim M. H., Hupfauf A., Gust R., Nelles P. A., Bernkop-Schnürch A. Lipophilic argi- 
nine esters: The gateway to preservatives without side effects. Mol. Pharmaceutics. 2020. V. 17. P. 3129-3139. doi: 10.1021/acs.molpharmaceut.0c00610.

46. Mahindra A., Sharma K. K., Rathore D., Khan S.I., Jacob M.R., and Jain R. Synthesis and antimicrobial activities of His (2-aryl)-Arg and Trp-His (2-aryl) classes of dipeptidomimetics. MedChemComm. 2014. V. 5. P. 671-676. doi: 10.1039/C4MD00041B.

47. Lohan S., Monga J., Chauhan C. S., and Bisht G.S. In vitro and in vivo evaluation of small cationic abiotic lipopeptides as novel antifungal agents. Chem. Bio. Drug Des. 2015. V. 86. P. 829-836. doi: 10.1111/cbdd.12558.

48. Armas F., Pacor S., Ferrari E., Guida F., Pertinhez T.A., Romani A.A., and Benincasa M. Design, antimicrobial activity and mechanism of action of Arg-rich ultra-short cationic lipopeptides. PloS One. 2019. V. 14, 1-22, doi: 10.1371/journal.pone.0212447.

49. Hoque J., Konai M.M., Sequeira S.S., Samaddar S., and Haldar $J$. Antibacterial and antibiofilm activity of cationic small molecules with spatial positioning of hydrophobicity: an in vitro and in vivo evaluation. J. Med. Chem. 2016. V. 59. 10750-10762. doi: 10.1021/ acs.jmedchem.6b01435.

50. Edwards-Gayle C.J., Castelletto V., Hamley I.W., Barrett G., Greco F., Hermida-Merino D., and Ruokolainen J. Self-Assembly, Antimicrobial Activity, and Membrane Interactions of Arginine-Capped Peptide Bola-Amphiphiles. ACS Appl. Bio Mater. 2019. V. 2. P. 2208-2218. doi: 10.1021/acsabm.9b00172.

51. Hegarty J., Krzeminski J., Sharma A., Guzman-Villanueva D., Weissig V., and Stewart D. Bolaamphiphilebased nanocomplex delivery of phosphorothioate gapmer antisense oligonucleotides as a treatment for Clostridium difficile. Int. J. Nanomedicine. 2016. V. 11. P. 3607-3619. doi: 10.2147/IJN.S109600.

52. Hegarty J.P., and Stewart D.B. Advances in therapeutic bacterial antisense biotechnology. Appl. Microbiol. Biotechnol. 2018. V. 102. P. 1055-1065. doi: 10.1007/ s00253-017-8671-0.

53. Gostenin V.B., Shchelik I.S., Sebyakin Yu.L. Synthesis and optimization of octavalent bolaamphiphile preparation with terminal d-mannose residues. Fine Chemical Technologies. 2015. V. 10. P. 39-43.

54. LaDow J.E., Warnock D.C., Hamill K.M., Simmons K.L., Davis R.W., Schwantes C.R., and Minbiole K.P. Bicephalic amphiphile architecture affects antibacterial activity. Eur. J. Med. Chem. 2011. V. 46. P. 4219-4226. doi: 10.1016/j.ejmech.2011.06.026.

55. Konai M.M., and Haldar J. Lysine-based small molecules that disrupt biofilms and kill both actively growing planktonic and nondividing stationary phase bacteria. ACS Infect. Dis. 2015. V. 1. P. 469-478. doi: 10.1021/acsinfecdis.5b00056.

56. Konai M.M., and Haldar J. Lysine-Based Small Molecule Sensitizes Rifampicin and Tetracycline against Multidrug-Resistant Acinetobacter baumannii and Pseudomonas aeruginosa. ACS Infect. Dis. 2019. V. 6. P. 91-99. doi: 10.1021/acsinfecdis.9b00221.

57. Boullet H., Bentot F., Hequet A., Ganem-Elbaz C., Bechara C., Pacreau E., and Moumné R. Small anti-
Microbial peptide with in vivo activity against sepsis. Molecules. 2019. V. 24. P. 1702. doi: 10.3390/molecules24091702.

58. Zhang E., Bai P.Y., Cui D.Y., Chu W.C., Нua Y.G., Liu Q., and Liu H.M. Synthesis and bioactivities study of new antibacterial peptide mimics: The dialkyl cationic amphiphiles. Eur. J. Med. Chem. 2018. V. 143. P. 1489-1509. doi: 10.1016/j.ejmech.2017.10.044.

59. Liu F., Yang L., Li Y., Junier A., Ma F., Chen J., and Sang $H$. In Vitro and In Vivo Study of Amphotericin B Formulation with Quaternized Bioreducible Lipidoids. ACS Biomater. Sci. Eng. 2020. V. 6. P. 1064-1073. doi: 10.1021/acsbiomaterials.9b01722.

60. Faig A., Arthur T.D., Fitzgerald P.O., Chikindas M., Mintzer E., and Uhrich K.E. Biscationic Tartaric AcidBased Amphiphiles: Charge Location Impacts Antimicrobial Activity. Langmuir. 2015. V. 31. P. 11875 11885. doi: 10.1021/acs.langmuir.5b03347.

61. Zhang Y., Algburi A., Wang, N., Kholodovych V., Oh, D.O., Chikindas M., and Uhrich K.E. (2017) Self-assembled cationic amphiphiles as antimicrobial peptides mimics: Role of hydrophobicity, linkage type, and assembly state, Nanomedicine: NBM, 13, 343-352, doi: 10.1016/j.nano.2016.07.018.

62. Gadhave A. Determination of hydrophilic-lipophilic balance value. 2014. Int. J. Sci. Res. V. 3. P. 573-575.

63. Konai M. M., Ghosh C., Yarlagadda V., Samaddar S., and Haldar $J$. Membrane active phenylalanine conjugated lipophilic norspermidine derivatives with selective antibacterial activity. J. Med. Chem. 2014. V. 57. P. 9409-9423. doi: 10.1021/jm5013566.

64. Kuppusamy R., Yasir M., Berry T., Cranfield C.G., Nizalapur S., Yee E., Kumar N. Design and synthesis of short amphiphilic cationic peptidomimetics based on biphenyl backbone as antibacterial agents. Eur. J. Med. Chem. V. 143. P. 1702-1722. doi: 10.1016/j.ejmech.2017.10.066.

65. Murugan R.N., Jacob B., Ahn M., Hwang E., Sohn H., Park H.N., Hyun J.K. De novo design and synthesis of ultra-short peptidomimetic antibiotics having dual antimicrobial and anti-inflammatory activities. PloS one. 2013. V. 8. P. 1-15. doi: 10.1371/journal. pone. 0080025 .

66. Teng P., Huo D., Nimmagadda A., Wu J., She F., Su M., and $H u$ Y. Small antimicrobial agents based on acylated reduced amide scaffold. Eur. J. Med. Chem. 2016. V. 59. P. 7877-7887. doi: 10.1021/acs.jmedchem.6b00640.

67. Bucki R., Niemirowicz K., Wnorowska U., Byfield F.J., Piktel E., Watek M., Savage P.B. Bactericidal activity of ceragenin CSA-13 in cell culture and in an animal model of peritoneal infection. Antimicrob. Agents Chemother. 2015. V. 59. P. 6274-6282. doi: 10.1128/AAC.00653-15.

68. Divakara S.S. M. L-Lysine based lipidated biphenyls as agents with anti-biofilm and anti-inflammatory properties that also inhibit intracellular bacteria. Chem. Commun. 2017. V. 53. P. 8427-8430. doi: 10.1039/C7CC04206J.

69. Zhou M., Zheng M., Cai J. Small Molecules with Membrane-Active Antibacterial Activity. ACS Appl. Mater. Interfaces. 2020. V. 12. P. 21292-21299. doi: 10.1021/ acsami.9b20161. 
70. Isaksson J., Brandsdal B.O., Engqvist M., Flaten G.E., Svendsen J.S., Stensen $W$. A synthetic antimicrobial peptidomimetic (LTX 109): stereochemical impact on membrane disruption. J. Med. Chem. 2011. V. 54. P. 5786-5795. doi: 10.1021/jm200450h.

71. Niu Y., Wang M., Cao Y., Nimmagadda A., Hu J., $W u Y$., Ye X.-S. Rational Design of Dimeric Lysine NAlkylamides as Potent and Broad-Spectrum Antibacterial Agents. J. Med. Chem. 2018. V. 61. P. 2865-2874. doi: 10.1021/acs.jmedchem.7b01704.

72. Ghosh C., Manjunath G.B., Konai M.M., Uppu D.S.S.M., Paramanandham K., Shome B. R., Haldar $J$. Aryl-alkyl-lysines: Membrane-Active Small Molecules Active against Murine Model of Burn Infection. ACS Infect. Dis. 2015. V. 2. P. 111-122. doi: 10.1021/ acsinfecdis.5b00092.
73. Ghosh C., Manjunath G.B., Akkapeddi P., Yarlagadda V., Hoque J., Uppu D.S.S.M., Haldar J. Small Molecular Antibacterial Peptoid Mimics: The Simpler the Better! J. Med. Chem. 2014. V. 57. P. 1428-1436. doi: 10.1021/jm401680a.

74. Ghosh C., Manjunath G.B., Konai M.M., Uppu D.S.S.M., Hoque J., Paramanandham K., Haldar J. Aryl-AlkylLysines: Agents That Kill Planktonic Cells, Persister Cells, Biofilms of MRSA and Protect Mice from SkinInfection. PLoS One. V. 10. P. 1-19. doi: 10.1371/journal.pone.0144094.

75. Ghosh C., Harmouche N., Bechinger B., Haldar J. ArylAlkyl-Lysines Interact with Anionic Lipid Components of Bacterial Cell Envelope Eliciting Anti-Inflammatory and Antibiofilm Properties. ACS Omega. 2018. V. 3. P. 9182-9190. doi: 10.1021/acsomega.8b01052. 